\title{
Investigation of failure of tubular joint of lightening rod
}

\author{
Peng Yiliang ${ }^{\mathrm{a}}$, Li Guotian ${ }^{\mathrm{b}}$, Chen Lei ${ }^{\mathrm{c} *}$ \\ HeNan Electric Power Survey\&Design Institute, Zhengzhou, 450007, China \\ a pyl_ok@126.com, bliguotian-heny@powerchina.cn, cchenleihe2008@163.com
}

\begin{abstract}
Keywords: Substation; Lightening Rod; Tubular joint; Finite element analysis
Abstract: The event that some lightning rod was fractured and collapsed at the tubular joint of lightning rod occurred in some transformer substation recently. The mechanical property of the tubular joint of lightning rod and frame column for transformer substation was analyzed in this paper based on the structural characteristic of the tubular joint. The finite analysis was conducted for such tubular joint by using finite element software ABAQUS. The reason of fracture and collapse of lightning rod was summarized based on the analytical results of both elastic and elastic-plastic analysis.
\end{abstract}

\section{Introduction}

The event that some lightning rod was fractured and collapsed at the tubular joint of lightning rod occurred in some transformer substation recently. The bottom of the lightning rod is steel tube with diameter of 330mm and thickness of $8 \mathrm{~mm}(\mathrm{Q} 235 \mathrm{~B})$. The supporting tube is steel tube with diameter of $480 \mathrm{~mm}$ and thickness of $6 \mathrm{~mm}$ (Q345B). The elevation of the top of the lightning rod is $40 \mathrm{~m}$. The lightning rod described above with typical tubular joint is shown in Fig. 1. The horizontal supporting tube $(\varnothing 480 \times 6)$ is connected to the lightning rod $(\Phi 330 \times 8)$. The top of the lightning rod shown in Fig. 1 is connected to the upper part of the lightning rod by the flange plate. The two sides of the horizontal supporting tube are connected with the frame beams and the bottom is connected with Herringbone column.

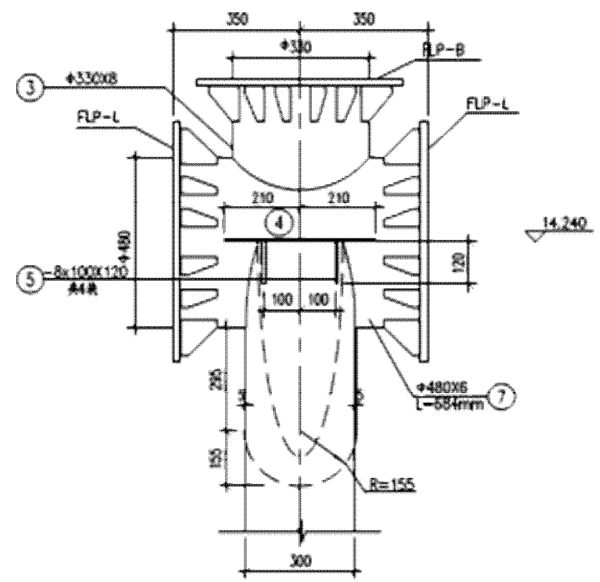

Fig.1 The structural form of the tubular joint of lightning rod

The design load cases for the tubular joint of the lightning rod is:

Design load case: lightning rod with connecting double ground wire;

Current load case (load condition when fractured): lightning rod with connecting single ground wire. It has been approved by careful calculation that the welding joint strength of the tubular joint of the lightning rod and horizontal supporting tube satisfies the requirements of the code. The photograph of the fractured section of the tubular joint is shown in Fig. 2. It is obvious that the failure at the tubular joint was mainly caused by the tearing of the horizontal supporting tube near the tubular joint. After the occurrence of the accident, to ensure the normal operation of the substation, the collapsed lightning rod is required to be recovered as soon as possible. This paper explored the mechanical behaviour of the tubular joint by finite element analysis based on the structural characteristic of the tubular joint of the lightning rod and the frame structure. The finite element software ABAQUS is 
used to perform the numerical analysis. The reason caused this failure is summarized based on the results of elastic and elastic-plastic analysis.
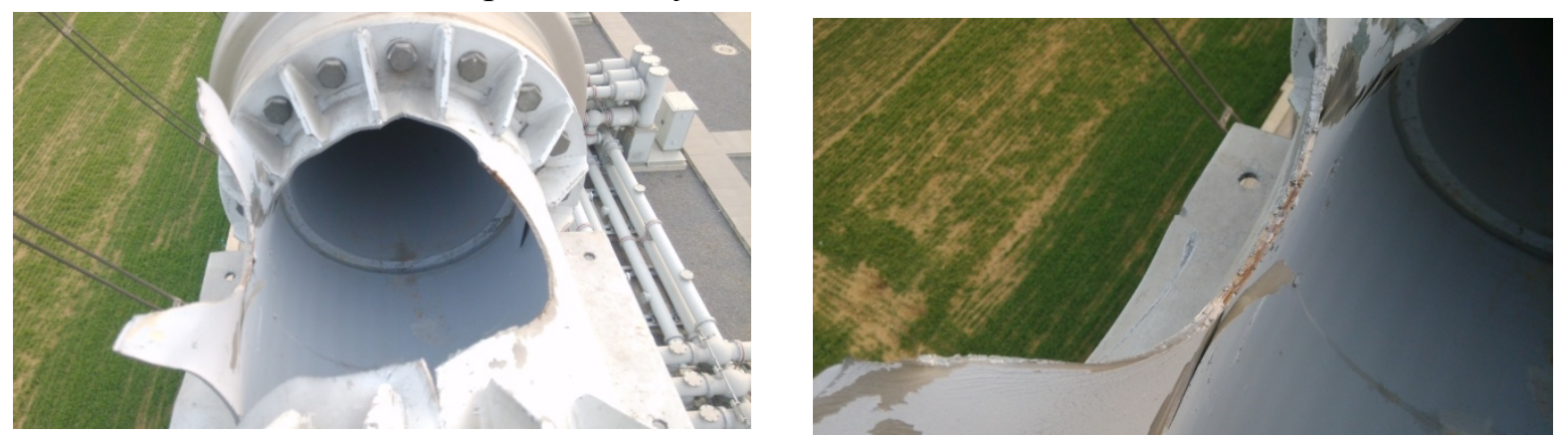

Fig. 2 The photograph showing the failure of the tubular joint of lightning rod

\section{The numerical analysis of tubular joint of lightning rod}

The testing method or combined testing and finite element analysis are used to determine the stress of the tubular joint and the safety state of the structure. Considering the current condition and restraint, the numerical simulation of the lightning rod is carried out by means of finite element analysis.

The general finite element software ABAQUS is used to conduct the analysis for the model of the collapsed lightning rod. The ideal elastic-plastic material is used with elastic modulus of $E=2.05 \times 105 \mathrm{MPa}$, Poisson's ratio of 0.3 and yield stress of $235 \mathrm{Mpa}$. The mises yielding criterion and plastic flow rule is adopted. Herringbone column support at the bottom end with the consolidation of boundary conditions. In order to truly reflect the actual internal force of the lightning rod, the bottom of the lightning rod is 5 times the diameter height, that is, $1.75 \mathrm{~m}$ is modeled, and the finite element model is shown in Figure 3. A reference point is established at the top center of the lightning rod and the reference point is established with the top circumference of the lightning rod. A reduced integral shell element S4R is adopted for the lightning rod, the stiffening plate and the horizontal support pipe. The element length is $16 \mathrm{~mm}$ after grid convergentce analysis.

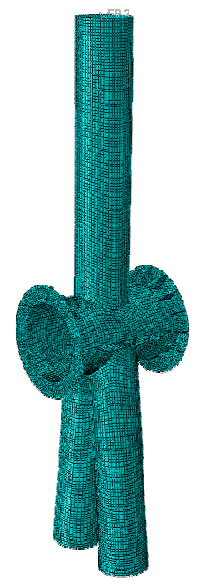

Fig. 3 Finite element model of tubular joint of lightening rod

The internal force of the lightning rod is analyzed and calculated by the STAAD.pro software: Connecting double ground line condition: axial force $13.52 \mathrm{kN}$, shear force $17.55 \mathrm{kN}$, bending moment 67.24kN.m.

Load case when lightning rod has fracture (connecting single ground wire): axial force $12.05 \mathrm{kN}$, shear force $11.00 \mathrm{kN}$, bending moment $52.49 \mathrm{kN} . \mathrm{m}$.

\section{The results of finite element elastic analysis}

Based on the most unfavourable load case with lightning rod connecting two ground lines under wind loading, the stress contour of the tubular joint of lightening rod is shown in Figure 4. The figure shows that the stress concentration occurs at the position of tubular joint with the maximum value of stress 
$2894 \mathrm{MPa}$. The average stress at the area of tubular line is $1700 \mathrm{MPa}$ or so which is much larger that the design strength of material.

Based on load case with lightning rod connecting single ground lines under wind loading, the stress contour of the tubular joint of lightening rod is shown in Figure 5. The figure shows that the stress concentration occurs at the position of tubular joint with the maximum value of stress $2211 \mathrm{MPa}$. The average stress at the area of tubular line is $1250 \mathrm{MPa}$ or so which is much larger than the design strength of material.

Fig.4 Stress contour of the tubular joint of lightening Fig.5 Stress contour of the tubular joint of lightening

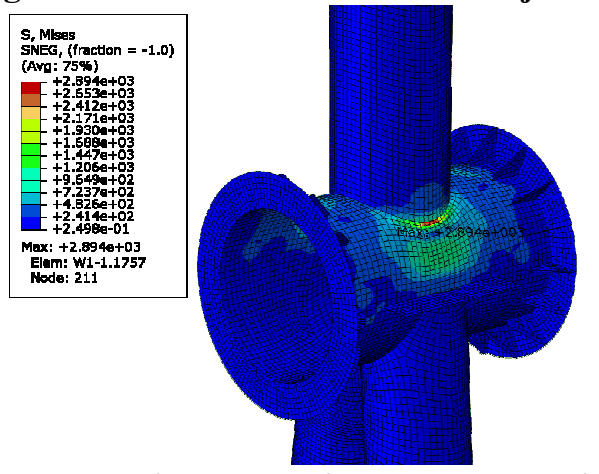

rod with connecting two ground lines

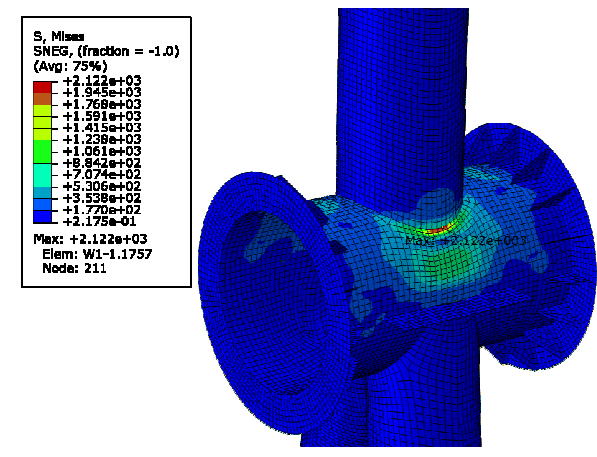

rod with connecting single ground line

\section{The results of finite element elastic-plastic analysis}

It is obvious that the maximum stress of horizontal supporting tube at tubular joint area is much larger than the yield strength of steel, which is impossible is practical structures. When the local high stress reaches the yield strength of steel, the local yield occurs at the position where the maximum stress appears. With the increase of loading, the stress is redistributed at the tubular joint area after the yield strength is reached and the yield area develops gradually until the yield failure occurs. The elastic-plastic analysis for the structure is required to derive more accurate results.

The results of elastic-plastic analysis for lightning rod with connecting single ground line are shown in Fig. 6. The curve shows the relationship between the vertical displacement at the loaction where the maximum stress appears and the dimentionless load which is the ratio of imposed load to design load.

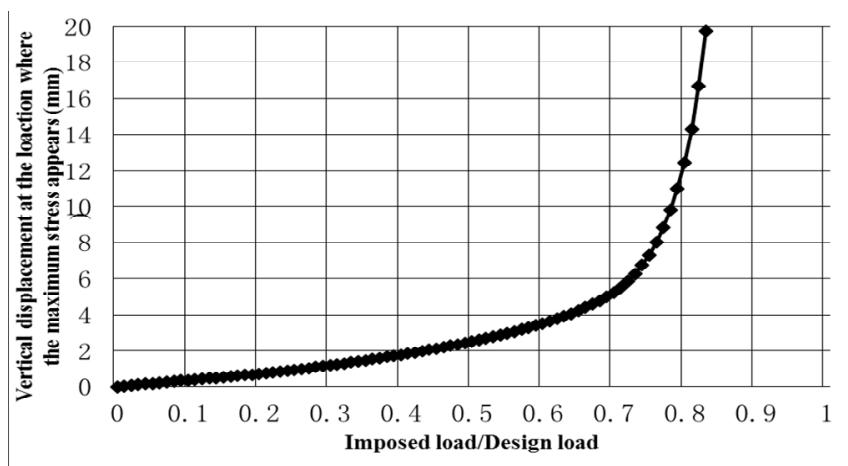

Fig.6 Relationship between the vertical displacement at the loaction where the maximum stress appears and the dimentionless load

Due to there is no clear priciple to determine the local instability for steel tubes subject to outplane bending, so based on clause description 10.3.4 in "Code for Steel Structure Design" (GB 50017 - 2003), the load corresponding to a local concave deformation of $1 \mathrm{D} / 100(4.8 \mathrm{~mm})$ is regarded as the load capacity for serviceability limit state and the value is 0.68 times design load from Fig.6. Similarly, the load corresponding to a local concave deformation of $3 \mathrm{D} / 100(14.4 \mathrm{~mm})$ is regarded as the load capacity for ultimate limit state and the value is 0.83 times design load from Fig.6. It is obvious that both serviceability limit state and the ultimate limit state is no satisfied for current design of the tubular joint of the lightning rod. 
The stress and deformation contour of the tubular joint of lightening rod corresponding to a local concave deformation of 1D/100 (4.8mm) is shown in Fig.7 and Fig.8.

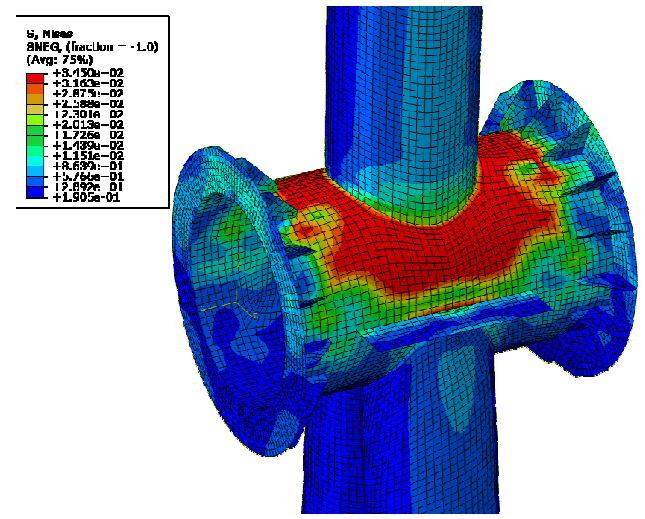

Fig.7 Stress contour of the tubular joint

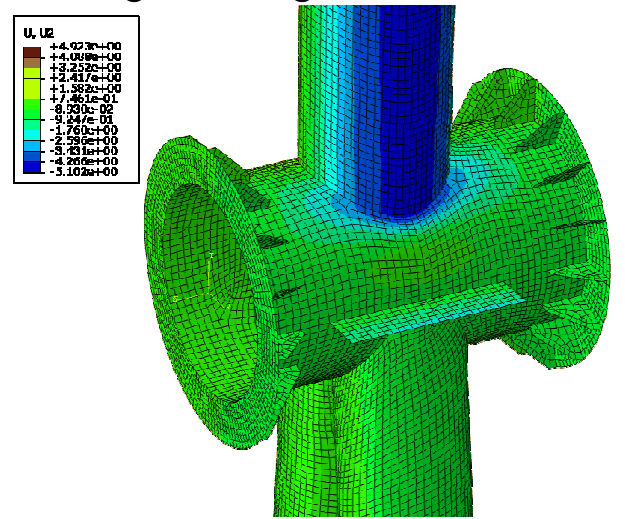

Fig.8 Deformation contour of the tubular joint

\section{Proposed reason for the the fracture of lightning rod}

By observing the fractured section, especially an old weld seam with a length of $390 \mathrm{~mm}$, it was found that the fracture of the bottom of lightning rod was not caused by one static loading, but is a typical fatigue failure. It was concluded that:

(1) The fatigue effect is not involved in the calculation of the lightning rod and tubular joint based on 《Technical code for designing building structures of substation》 (NDGJ96-92) .

(2) The results of elastic analysis indicate that the stress of the supporting horizontal tube under design load reaches $2979 \mathrm{MPa}$, and 2000MPa for average stress. The values of stress are much larger than the design strength of material.

(3) The results of elastic-plastic analysis indicate that the imposed loads corresponding to serviceability limit state and ultimate limit state are both smaller than the design load, which indicate the safety reliability of original design is not sufficient.

(4) Considering the dynamic influence caused by the wind loading as a cyclic loading, the static analysis of the tubular joint cannot capture the accurate mechanical behaviour of the structure. If the fatigue effect is involved in the analysis, the safety reliability of original design is obvious worse.

(5) The swing of the ground line may has some dynamic influence on the mechanical behaviour of the structure, which requires further research in the future.

(6) The welding position at the tubular joint area subject to complex forces of flexure, compression and shear. The thermal influence area of the side of the steel pipe having imperfections is easy to crack, and the plasticity and toughness of the steel in the heat affected zone decrease under the cyclic stress, and the fracture mode is changed from plastic fracture to brittle fracture.

\section{Conclusions}

Finite element analysis is carried out for a fractured lightning rod of a $500 \mathrm{kV}$ substation. Based on the analysis results, the main reasons of the failure are summarized: the fatigue effect is not involved in the code and this effect was neglected in the original design; the stress concentration of $\mathrm{T}$ shaped tubular joint is obvious, which may accelerate the appearance of crack at thermal influence area; the plasticity and toughness of the steel in the heat affected zone decrease under the cyclic stress, and the fracture mode is changed from plastic fracture to brittle fracture.

\section{Reference}

[1] Code for Steel Structure Design (GB 50017-2003), Beijing: China Planning Publishing, 2003.

[2] 《Technical code for designing building structures of substation》 (NDGJ96-92), Beijing: China electric power planning and Design Institute, 1992. 
International Forum on Energy, Environment Science and Materials (IFEESM 2015)

[3] HKS: ABAQUS Version 6.6 Standard user's guide and theoretical manual, Hibbit, Karlsson and Sorensen Inc., Pawtucket, Rhode Island, USA (2006). 